\title{
Research on the Influence of the Load Peaks and Troughs with New Energy Access
}

\author{
Yang Zhao \\ Jinzhou Power Supply Branch \\ State Grid Liaoning Electric Power Supply Co. Ltd \\ Jinzhou, China \\ e-mail: liyuca@126.com
}

\author{
Xinyu Yang \\ Jinzhou Power Supply Branch \\ State Grid Liaoning Electric Power Supply Co. Ltd \\ Jinzhou, China \\ e-mail: yangxy1885@126.com
}

\begin{abstract}
The new energy power generation technology in our country has made some progress, some areas have practical applications. Micro grid system is made up of new energy can improve the reliability of power grid in our country, and can improve the quality of electric energy. New energy of micro grid system can improve the reliability of power grid in our country, and can improve the quality of electric energy. External power of new energy power station is very strong when degeneration. This article will focus on the characteristics analysis and research on characteristics of photovoltaic and wind power, analyzes the situation by a variety of new energy power generation in the influence of power system. The traditional wind-light complementary theory assumes that questioned, and analyses the influence of a variety of new energy power generation combination cases the influence of power system.
\end{abstract}

Keywords- New Energy; Load Peaks; Troughs; Influence

\section{INTRODUCTION}

The new energy power generation technology in our country has made some progress, some areas have practical applications. Micro grid system is made up of new energy can improve the reliability of power grid in our country, and can improve the quality of electric energy. The economic development of our country has already entered the digital era, with the increment of power consumption in all walks of life, only for them to provide quality and reliable power supply to provide safeguard for the development of economy. Power grid vulnerability during rush hour will be shown, and new energy power generation can to a certain extent, ease the situation, not only save the cost, also can provide quality and reliable electricity, and can avoid economic loss due to overload power outages, so as to create conditions for the rapid development of economy in our country[1-3].

New energy power generation and the difference between the traditional power generation: first, the power of new energy power station is an artificial force change and scheduling, the hair power natural environment has strong links with the outside world, the external performance is strong degeneration. Its power factors such as temperature, humidity, day and night, season changing. Second, the new energy power generation compared with the traditional power generation, its cost is lower, and emissions of greenhouse gases in the process of generating and harmful substances are very few, even no[4-8]. This article will focus on the characteristics analysis and research on characteristics of photovoltaic and wind power, and on the basis of the analysis of new energy power generation peak in cutting, voltage stability, reactive power support and the influence of the network energy loss, etc. This article discusses the characteristics of photovoltaic and wind power based on the analysis of existing in the new energy power generation effect, such as the peak is the peak effect and the effect of the peak, etc[9-11]. The traditional wind-light complementary theory assumes that questioned, and analyses the influence of a variety of new energy power generation combination cases the influence of power system. New energy was simulated under the condition of different access points and different access capacity influence on system network loss; Discuss the influence of the reactive power on voltage stability.

\section{PHOTOVOLTAIC POWER GENERATION}

Photovoltaic power generation systems are designed around the pv cells. A typical piece of photovoltaic battery output power is less than $5 \mathrm{w}$, is about $0.5 \mathrm{~V}$, dc voltage so photovoltaic cells must be in series, to produce enough electricity for high power applications. Pv cells can be regarded as special $\mathrm{p}-\mathrm{n}$ junction, its work on the project mainly use diode equation described, its typical equivalent circuit diagram of figure 1 : 


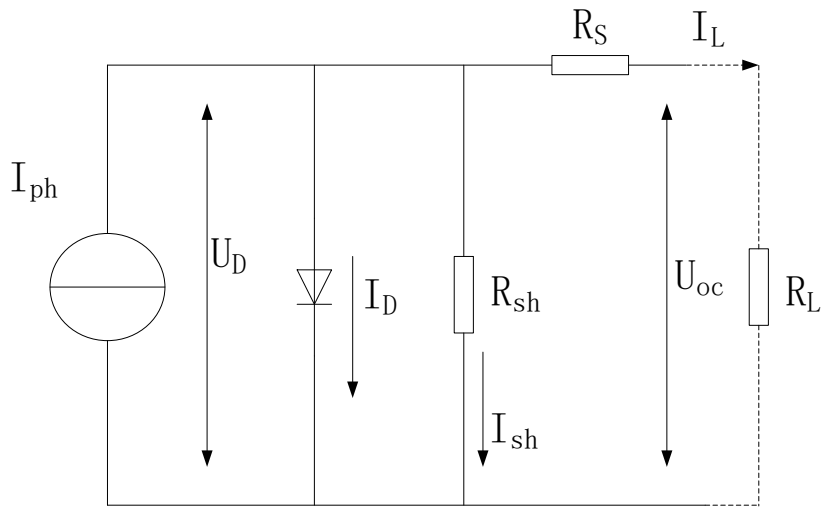

Figure 1. The equivalent circuit of photovoltaic battery

Power output characteristics of photovoltaic cells will be affected by the irradiance and temperature. Figure 2 shows the SPR - 305 - type WHT photovoltaic cells in the i-v curve of the fixed temperature 25 degrees Celsius and PV curve. Can be seen that: fixed temperature, i-v curve can move up as light intensity increases with the whole, shows that short circuit current ISC rise with the increase of light intensity; At the same time, the open circuit voltage of the battery With the increase of light intensity and slightly increased. Can be seen from the photovoltaic cells have the output voltage and current limit, namely photovoltaic cells run even in the case of short circuit and short circuit phenomenon will not occur.
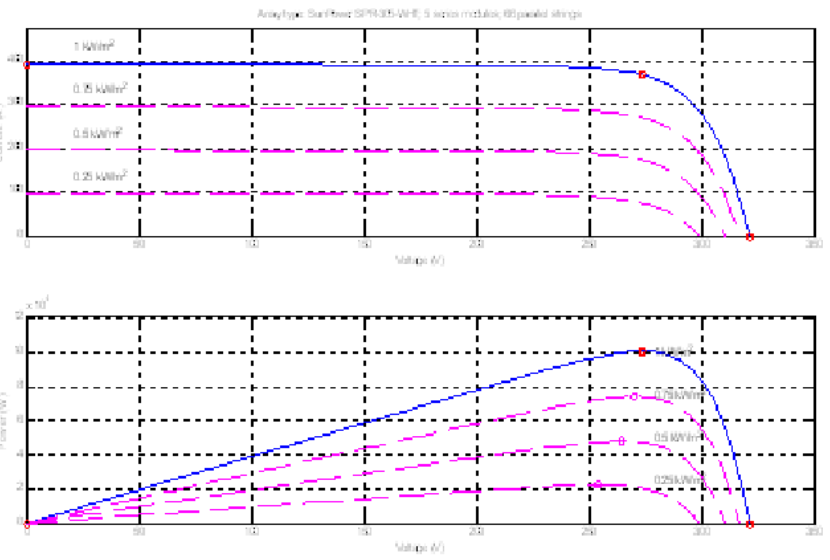

Figure 2. PV cell characteristic under different irradiance and fixed temperature

Figure 3 shows the photovoltaic battery output characteristic under the fixed irradiance, its output characteristic and the relationship between the temperature. As can be seen by the figure, the fixed irradiation intensity with the increase of temperature, the battery open circuit voltage of A shift to the left, that temperature had significant effect on the open circuit voltage of the battery; At the same time, the battery of the constant current source area, the change of environmental temperature keep constant shows the battery short-circuit current B is affected by temperature is not very significant.
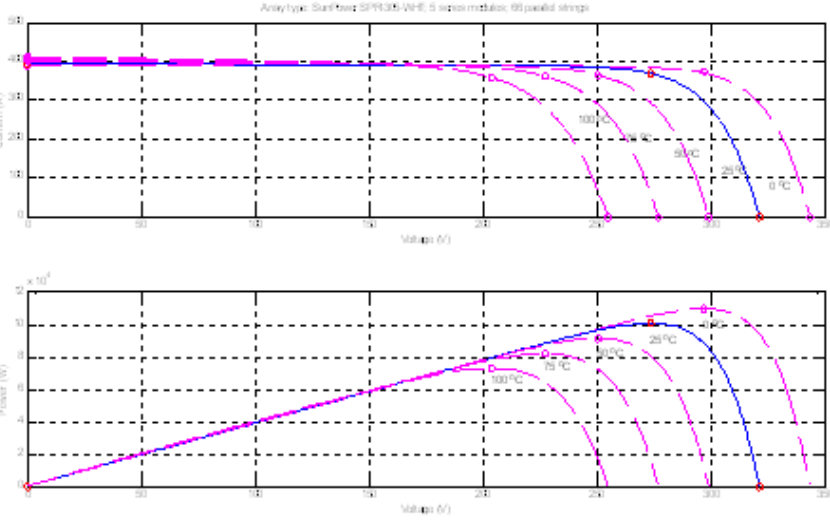

Figure 3. PV cell characteristic under different temperature and fixed irradiance

Through the above analysis, the photovoltaic battery output is a nonlinear curve, and the output power under the dual effects of irradiation intensity and environment temperature.

\section{WIND POWER CHARACTERISTICS}

Wind power generation through the use of wind power to drive the generator. The wind through the leaves will produce lift, which places a rotating force to the blade. Rotating blades through the axis of rotation to drive the generator to generate power, on the path of the blades to the generator can have variable speed gear box, also can not. Generator type can be synchronous generator, also can be asynchronous generator. Its structure form by the user to select the type of different and different. Principle of wind turbine power generation such as (1).

$$
P=\frac{1}{2} \rho A v^{3}
$$

Wind from the leaves swept area of absorbing kinetic energy, although the type is given in wind power, but to the wind power will fall to a certain extent, on the decline in multiples called power coefficient, for its expression

$$
\begin{gathered}
C_{p}=\frac{P_{\text {wind turbine }}}{P_{\text {air }}} \\
P_{\text {wind turbine }}=C_{p} P_{\text {air }}=\frac{1}{2} C_{p} \rho A v^{3}
\end{gathered}
$$

A maximum of $C_{p}$ is defined by Betz limit, described as a wind turbine could never learn more than $59.3 \%$ of the power from the air stream. In fact, wind turbine $C_{p}$ maximum range is $25 \% \sim 45 \%$. In addition, use more widely in engineering a parameter for the tip speed ratio, the expression are meant to be:

$$
\lambda=\frac{\omega R}{v}
$$


Tip speed ratio and power coefficient is dimensionless, can be used to describe any size of the performance of the wind turbine. Wind energy utilization and tip than relations as shown in figure 4, can be seen from the figure, the power factor can only under certain tip velocity to achieve maximum value, that is a fixed speed wind turbines can only under a fixed speed can achieve maximum power coefficient.

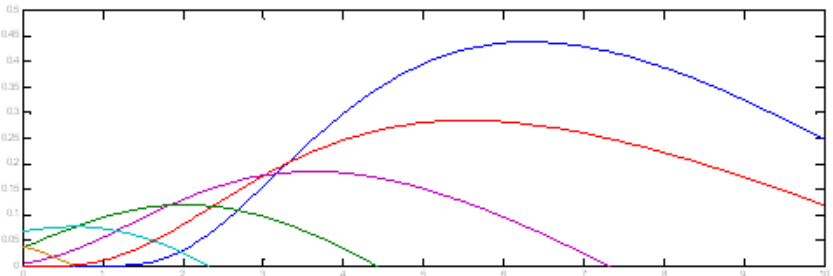

Figure 4. The relationships of wind energy utilization and tip ratio

\section{NEW ENERGY ACCESS FOR THE INFLUENCE OF LOAD PEAKS AND TROUGHS}

New energy access system, the aim is to ensure that the user power supply under the premise of safe and reliable as far as possible to reduce fossil fuel power generation plants. But the new energy power generation is influenced by natural factors on the timeline, part scheduling belongs to. Ideally the network load are in a peak period of time, the new energy power just in peak power generation period; Network load is in a valley value time, generating new energy power also come in a valley. Reality is not the case, however, found in large amounts of data test research: new energy access system's influence on the system load "is the peak effect", "negative peak effect" and "peak effect". Figure 5 is "is the peak effect" simulation analysis diagram, wind power is set to 0.5 times the initial curve, photovoltaic power generation is set to 0.15 times the initial curve, set of wind power in $1 \sim 15$ and $46 \sim 60$ times not to generate electricity. To simplify the problem, it is assumed that the fossil fuel power plants generating lower limit for the minimum load. The figure shows that the fossil fuel power generation capacity in the trough time doesn't change, but in the peak period of time due to the participation of new energy power generation capacity to reduce. The end result is a peak value and the trough of fossil fuel power plants in the value of the difference is reduced, therefore the spinning reserve capacity can reach the purpose of saving fossil fuel with the decrease of the appropriate, the new energy access is a good way of new energy access.

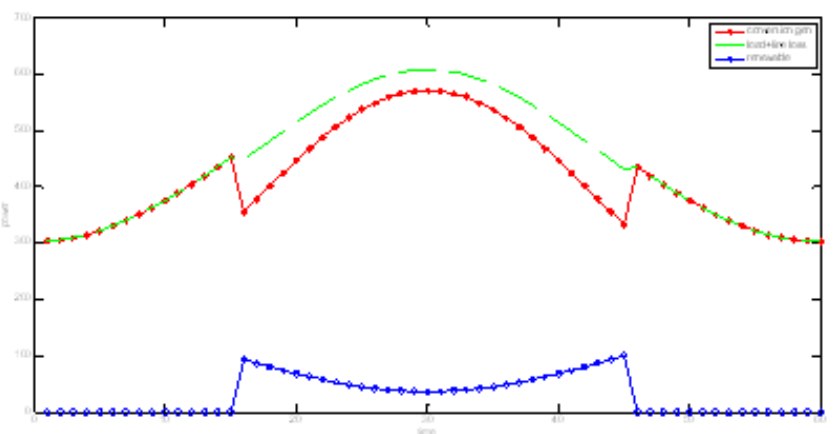

Figure 5. Positive peak effect of new energy power generation access
Figure 6 for "peak inverse effect", the wind power is set to 0.5 times the initial curve, solar power is set to 0.15 times the initial curve, wind power and solar power set in $15 \sim 45$ hours don't generate electricity. The figure shows that fossil fuels in the peak period did not change, but in the trough time due to the participation of new energy power generation make fossil fuels power limit happened through war. The end result is a peak value and the trough of fossil fuel power plants in the value of the difference increases, its power limit should be the direction to reduce power direction adjustment, if the lower limit of power station power be bound by objective conditions can not be adjusted, so the security of the system will be threatened.

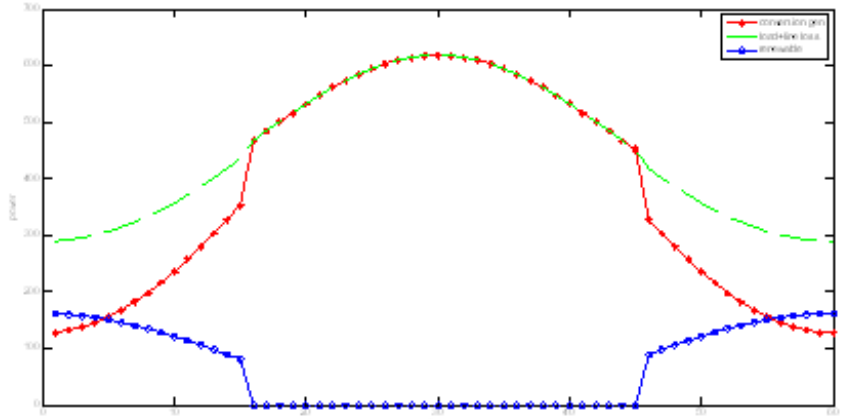

Figure 6. Negative peak effect of new energy power generation access

Figure 7 for "peak effect", the wind power is set to 0.8 times the initial curve, solar power is set to 0.5 times the initial curve, wind power and solar energy power set in the $1 \sim 15$ and $46 \sim 60$ hours don't generate electricity. The figure shows that fossil fuels in the trough time doesn't change, in the peak period of time due to the participation of new energy power generation to reduce, but as a result of new energy power generation access networks too ambassador to fossil fuel power generation capacity in part time limit through the phenomenon happens, the safe running of the system is under threat.

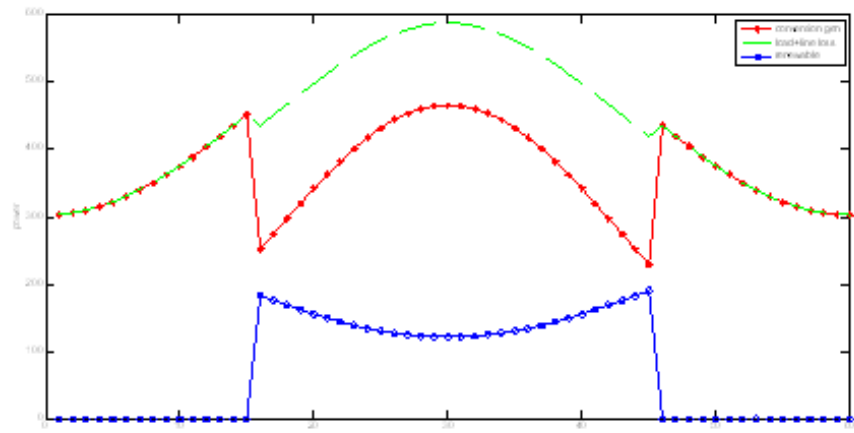

Figure 7. Overload peak effect of new energy power generation access

A single type of new energy power generation has the distinctive features of greater power fluctuation. Photovoltaic power generation in a day, for example, the rule is: the lowest altitude of the sun, photovoltaic maximum power generation, photovoltaic panels at night without electricity. If the system of photovoltaic power 
generation capacity is large, then systematically power output will be occurred the phenomenon of volatility, realtime power control system will become very difficult. In order to overcome the single type of new energy power fluctuation big shortcoming, many scholars put forward many new energy hybrid power concept. These theories with wind-light complementary research most, but is important to emphasize that most research papers are hypothetical wind power at night full power power, reducing power generation in the daytime or not electricity, wind power can compensate for photovoltaic energy gaps in the night, photovoltaic power generation can be made of the energy gaps of wind power in the daytime. This scenario has certain rationality, in most of the wind field is suitable; But the field data tests show that the part of the wind field day wind resources may be the equilibrium constant, basic remain in a level power; There is also a part of the wind field wind resources may be the biggest in the daytime and night minimum, these obviously cannot adopt the assumptions mentioned above. Figure 8 is pv curve and composite picture of wind power curve under different conditions. Time delay axis curve of wind power and photovoltaic power generation curve geometry of phase center axis, vertical axis represents active power. By changing the center axis of phase difference to change the new energy maximum power generation time (time seq) position on the timeline.
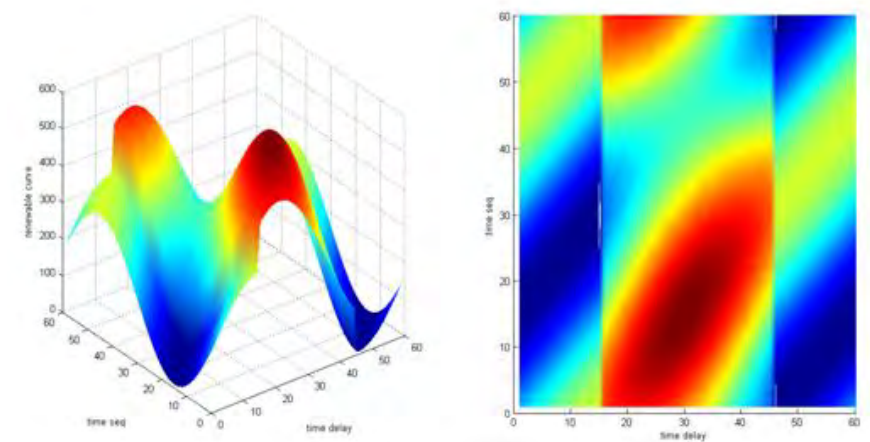

Figure 8. Power output characteristics under different combinations of new energy

In figure 8 shows different trends of new energy power generation capacity under the access to the system analysis can be obtained as shown in figure 9 fossil fuel power generation power simulation diagram. Figure set in fossil fuel power generation lower limit is 150 , wind power curve and photovoltaic power generation curve is 0.6 times the initial curve. The figure 9 shows that the combination of wind power and photovoltaic power situation there are many possibilities, does not necessarily comply with windlight complementary hypothetical mentioned before.
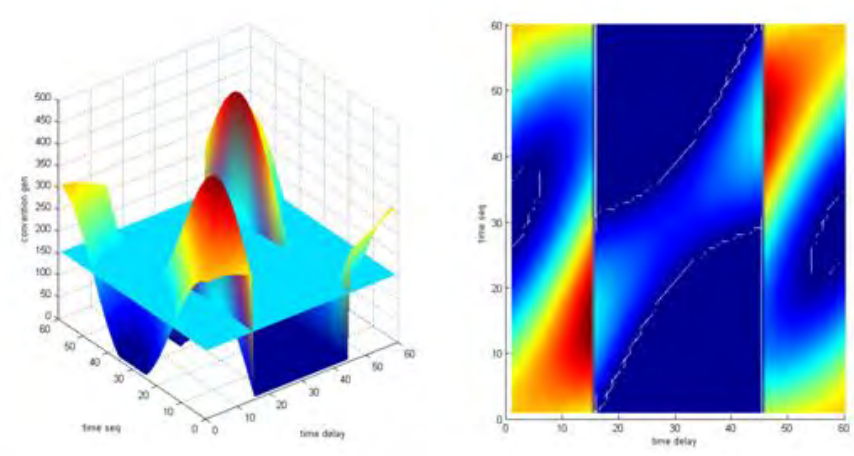

Figure 9. Fossil fuel power plant output under different combination of new energy

From the above analysis, the new energy access to the system capacity will be affected by the natural environment and valley load of fossil fuel power plants, reserves and a variety of new energy mix various factors, the combination of them form diversified characteristics. So on the analysis of new energy power generation's influence on the actual system, can't take all kinds of new energy power generation situation analysis of the combination of simple, should analyze their concrete composite structure, understand their portfolio is good or bad combination.

\section{CONCLUSION}

In photovoltaic power generation is discussed in detail in this chapter and characteristics on the basis of analysis of wind power in the new energy power generation as the peak effect, is the peak effect and the effect of the peak, etc. The traditional wind-light complementary theory assumes that questioned, and analyses the influence of a variety of new energy power generation combination cases the influence of power system.

\section{REFERENCES}

[1] P. Cbiradeja and R. Ramakinnar, “An Approach to Quantify the Technical Benefits of Distributed Generation” , IEEE Transactions on Energy Conversion, vol.19 .pp.764-773. Nov 2004.

[2] V. VAPNIK, “ The nature of statistical learning theory [M] . New York, USA : Springer, pp.17-33. 1995.

[3] V. VAPNIK, “An overview of statistical learning theory" , IEEE Transactions on Neural Network, vol.10 .pp.988-999. Mar 1999.

[4] F. Wang, E. Yu and J. Y. Zhou, "Energy Management System (EMS) part four : electric power load forecasting ", Automation of Electric Power Systems, vol.21 .pp.66-69. Jun 1997.

[5] L. Han, X. S. Han and Z. H. Yun, "Method for ultrashort term multi-node load forecasting", Automation of Electric Power Systems, vol.31 .pp.30-34. Aug 2007

[6] W. F. Tinney and C. E. Hart, "Power Flow Solution by Newton's Method" , Power Apparatus and Systems, IEEE Transactions on, vol.11 .pp.1449-1460. Apr 1967.

[7] R. K. Singh and S. K.. Goswami., "Optimum Siting and Sizing of Distributed Generations in Radial and Networked Systems" Electric Power Components and Systems, vol.2 .pp.127-145. Nov 2009.

[8] Z. C. Cai and Z. M. He, "Correlation Theory Applied in Li-brary and Information Analysis”, Modern Information, vol.5 .pp.151 152. May 2006

[9] L. J. Wu and H. Z. Wang, "Application of Differential E2 volution Algorithm in Optimal Dispatching of Hydropower 
Station”, Water Resources and Power, vol.6 .pp.190-192. May 2009.

[10] K. J. P. Macken, M. H. J. Bollen and J. M. Belmansr, "Tigation of Voltage Dips Through Distributed Generation Systems", IEEE Trans on Industry Applications, vol.40 .pp.1686-1693. Aug 2004.
[11] A. Keane, M. O'Malley, “Optimal Allocation of Embedded Generation on Distribution Networks, Power Systems, IEEE Transactions on, vol.20 .pp.1640-1646. Aug 2005 